\title{
Compensation of Power Fluctuations of PV Generation System by SMES Based on Interleaving Technique
}

\begin{abstract}
Seung-Tak Kim* and Jung-Wook Park ${ }^{\dagger}$
Abstract - This paper proposes the enhanced application of superconducting magnetic energy storage (SMES) for the effective compensation of power fluctuations based on the interleaving technique. With increases in demand for renewable energy based photovoltaic (PV) generation system, the output power fluctuations from PV generation system due to sudden changes in environmental conditions can cause serious problems such as grid voltage and frequency variations. To solve this problem, the SMES system is applied with its superior characteristics with respect to high power density, fast response for charge and discharge operations, system efficiency, etc. In particular, the compensation capability is effectively improved by the proposed interleaving technique based on its parallel structure. The dynamic performance of the system designed using the proposed method is evaluated with several case studies through time-domain simulations.
\end{abstract}

Keywords: Distributed power generation, Interleaving technique, Renewable energy system, superconducting magnetic energy storage.

\section{Introduction}

With increases in demand for renewable energy based distributed generation (DG) systems such as wind and photovoltaic (PV) system, the output power fluctuations from DGs due to sudden changes in environmental conditions can cause serious problems such as grid voltage and frequency variations [1]. To make better use of renewable energy, energy storage devices could be applied to compensate for the power fluctuation.

The energy storage system (ESS) has recently emerged as a more promising device for stabilizing power systems as it has both real and reactive power control abilities. In that sense, flywheel energy storage [2], the electric double layer capacitor (EDLC) [3, 4], and the battery energy storage system (BESS) [5] have been proposed to smooth the power fluctuations. Also, superconducting magnetic energy storage (SMES) is an outstanding power compensator because of the fast-response charging and discharging times and the high energy storage efficiency of the system [6-10].

The interleaving technique is used in various applications with the transistor stages in parallel [11]. The interleaved DC/DC converter topology, as compared with the traditional paralleling of output stage transistors, achieves high efficiency, current distribution, a low ripple reduction, and a small component capacity. In order to have a small input current ripple and zero reverse-recovery loss, a coupling

$\dagger$ Corresponding Author: School of Electrical and Electronic Engineering, Yonsei University, Seoul, Korea. (jungpark@yonsei. ac.kr)

* School of Electrical and Electronic Engineering, Yonsei University, Seoul, Korea. (miso2me@yonsei.ac.kr)

Received: November 19, 2014; Accepted: June 29, 2015 inductor is used [12]. The control method has been studied in order to increase the efficiency during light-load conditions [13]. Also, research has been done to solve the current imbalance of each phase [14].

Therefore, when the interleaving technique is applied to SMES, the ripple current of SMES is reduced $[15,16]$. The interleaving technique improves the power quality and the power compensation capabilities. Moreover, the compensation capability is effectively improved by the proposed interleaving technique based on its parallel structure. This paper proposes the enhanced application of SMES for the effective compensation of power fluctuations based on the interleaved technique. To show the effectiveness of the proposed system, its dynamic performance is evaluated using the power systems computer aided design/electromagnetic transients including DC $\left(\mathrm{PSCAD} / \mathrm{EMTDC}^{\circledR}\right)$ based simulation.

\section{System Description}

The proposed power distribution network is shown in Fig. 1. It consists of a $10 \mathrm{MW}$ grid-connected PV generator and SMES. For rapid response of PV power compensation, the SMES system is directly connected to the DC link of the PV system and shares with the voltage source converter (VSC), because of the slow response of the VSC during the $\mathrm{DC}$ power transfer to $\mathrm{AC}$ power.

\subsection{PV generation system}

The PV array is modeled by an equivalent circuit of about 43,000 solar modules, which reflects its non-linear 


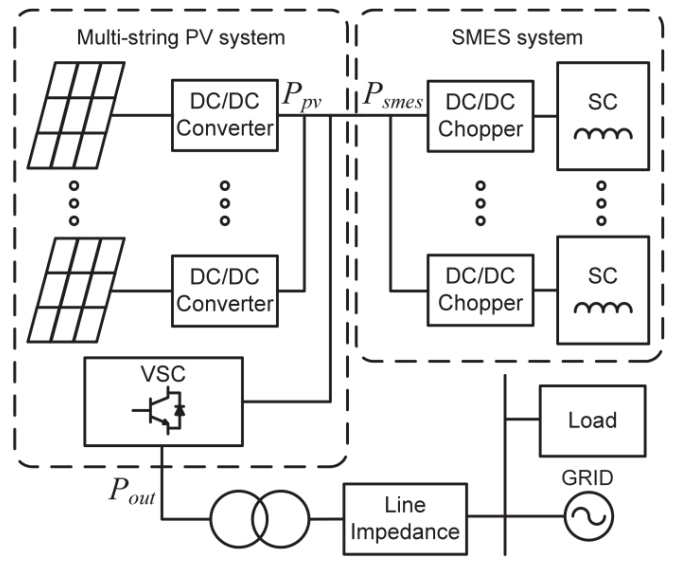

Fig. 1. The distribution power system with PV generation and SMES.

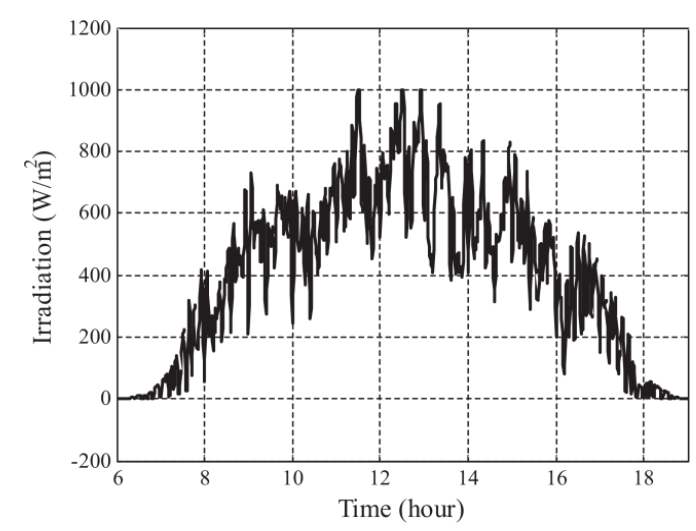

Fig. 2. The irradiation profile of cloudy day.

current-voltage characteristic. In addition, the grid-connected PV system is configured by a multi-string system, where several PV strings are interfaced with their own DC/DC converter to a common inverter. The output characteristics of the PV array always vary with the weather conditions, such as the irradiation levels and atmospheric temperatures. The irradiation profile on a cloudy day is shown in Fig. 2.

Therefore, the maximum power point tracking (MPPT) is important, and the DC-DC converters are used for MPPT, depending on the perturbation and observation $(\mathrm{P} \& \mathrm{O})$. Under the multi-string structure, each PV string individually tracks the maximum power with high generation efficiency. The VSC transmits real power from the DC-DC converter while maintaining a constant DC link voltage to ensure the reactive power demand of the grid. The VSC control uses the pulse width modulation (PWM) method.

\subsection{SMES system}

The SMES system consists of a superconducting coil (SC), a DC/DC chopper, and a VSC. The stored energy in the $\mathrm{SC}, E_{\text {smes_n } n}$, is commonly given as a specification, which can be expressed as
Table 1. Specifications of SMES system

\begin{tabular}{c|c}
\hline System & Specification \\
\hline Inductance of SC coil & $1 \mathrm{H} \times 6$ \\
\hline Maximum stored energy & $0.6 \mathrm{MJ} \times 6$ \\
\hline Rated dc current & $1100 \mathrm{~A}$ \\
\hline Rated dc voltage & $1 \mathrm{kV}$ \\
\hline
\end{tabular}

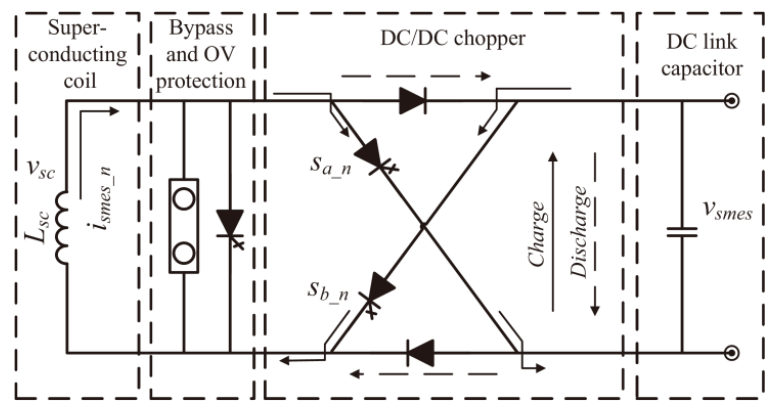

Fig. 3. The DC/DC chopper topology for SMES operation.

$$
E_{\text {smes_n }}=\frac{1}{2} L_{s c} i_{\text {smes_n }}^{2}
$$

where $L_{s c}$ is the self-inductance of the $\mathrm{SC}$, and $i_{\text {smes } n}$ is the coil current. The SMES system is designed such that it has a maximum current and rated voltage of $1.1 \mathrm{kA}$ and $1 \mathrm{kV}$, respectively. Table 1 summarizes some parameters of the SMES for simulation.

The charging and discharging of the SMES are accomplished by a DC/DC chopper between the DC link and the SMES coil. Fig. 3 shows in detail the DC/DC chopper topology for SMES operation. The two switching devices, $s_{a n}$ and $s_{b n n}$ in the DC-DC chopper, are switched on and off simultaneously for the charging and discharging operations [17]. It has a switch for the bypass on standby mode and overvoltage $(\mathrm{OV})$ protection.

The VSC connects a DC link capacitor to the AC network, and it is the same as the VSC of the PV system. On the power generation side, the SMES has an auxiliary role of power compensation. Moreover, the response of the VSC is slower than that of the DC/DC converter due to the DC power transfer to AC power. Therefore, the proposed SMES system is directly connected to the DC link of the PV system and shares with the VSC of the PV system.

The proposed interleaved technique is applied to the SMES and PV generation systems in distribution power network as shown in Fig. 1. The interleaving technique is simply achieved by the PWM carrier signals of all of the converters in parallel operating out of phase. Because the current ripples of the SMES are out of phase, they tend to cancel each other and reduce the current ripple caused by the SMES. In this paper, the proposed interleaved SMES system uses six $(N=6)$ SCs and DC/DC choppers. 


\section{Control of SMES Converter}

\subsection{Compensation of power fluctuation}

The control block diagram of the proposed interleaved SMES system is shown in Fig. 4. Compensation of the output power fluctuations is the primary control object and it requires fast response. The reference power that is compensated by the SMES, $P_{\text {smes ref, }}$, can be computed by the 3rd order high pass Butterworth filter, as expressed in

$$
P_{\text {smes_ref }}=\frac{s^{3}}{s^{3}+2 \omega_{c} s^{2}+2 \omega_{c}^{2} s+\omega_{c}^{3}} P_{p v}
$$

where $P_{p v}$ is the PV generation power and $\omega_{c}$ is the cut-off frequency. In this study, the time constant, which is related to the cutoff frequency, is set to be $334 \mathrm{~s}$. The degree of smoothing can be modified by adjusting the cut-off frequency.

\subsection{Energy maintenance of the SC}

Compensation of the output power fluctuations operates according to the high pass filtering, which removes the DC component. The remaining energy after compensating the fluctuation for one day is the same as the previous charged

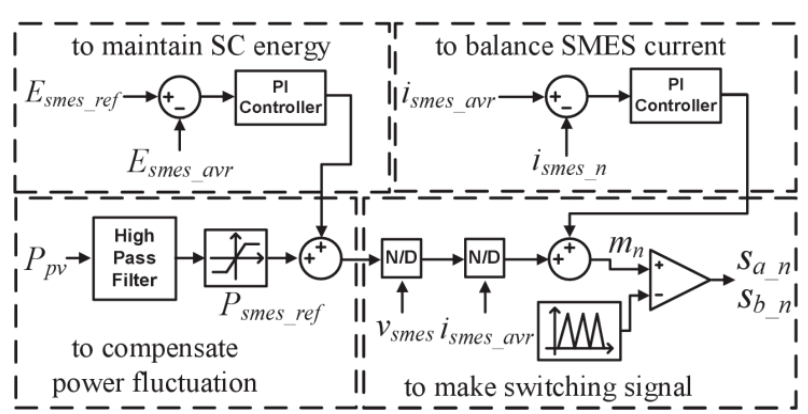

Fig. 4. Block diagram of the SMES controller.

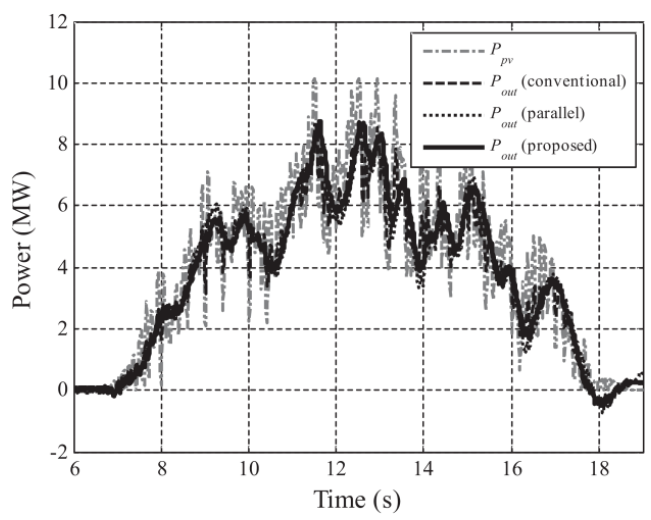

(a) energy. Due to the small losses in the SMES and the DCDC chopper circuit, and especially the VSC control reference error by affecting the SMES, the remaining energy after compensation for one day can be changed. Therefore, it is necessary to maintain the energy of the SMES. The energy reference, $E_{\text {smes ref }}$, is about $67 \%$, and the SC current is $0.9 \mathrm{kA}$. Note that the maintenance control response of the SMES energy must be slower than the compensation control response of the power fluctuations.

\subsection{Balancing of SMES current}

Interleaved system requires a current loop in each phase to control the dc current per phase. The current balancing between interleaved phases is essential. While an unbalanced current causes more thermal stress in one phase, it is necessary in order to avoid the overheating of some components and to prevent saturation [18]. Therefore, the current control loop with the balancing current reference, $i_{\text {smes_avr }}$, which is the average value of each SC current, is used for interleaved controlling the phase individually.

\subsection{Switching signal generation}

The power reference for charging and discharging is normalized by the DC link voltage, $v_{\text {smes }}$, and the average current reference, $i_{\text {smes avr }}$. Then the modulating signal of the SMES per interleaved phase, $m_{n}$, is calculated with the sum of the normalized reference and the current balancing reference. The carrier signal is a saw wave from -1 to 1 . When the modulating signal is larger than the carrier signal, a turn-on command is issued to $s_{a_{-} n}$ and $s_{b_{-} n}$. Once the modulating signal is smaller than the carrier signal, $s_{a_{-} n}$ and $s_{b n n}$ are switched off. Changing the modulating signal can control the current of the SC as follows [19]

$$
\frac{d i_{\text {smes } \_n}}{d t}=-\frac{1}{L_{s c}} \overline{v_{s c_{-} n}}=-\frac{1}{L_{s c}} m_{n} \cdot v_{\text {smes }}
$$

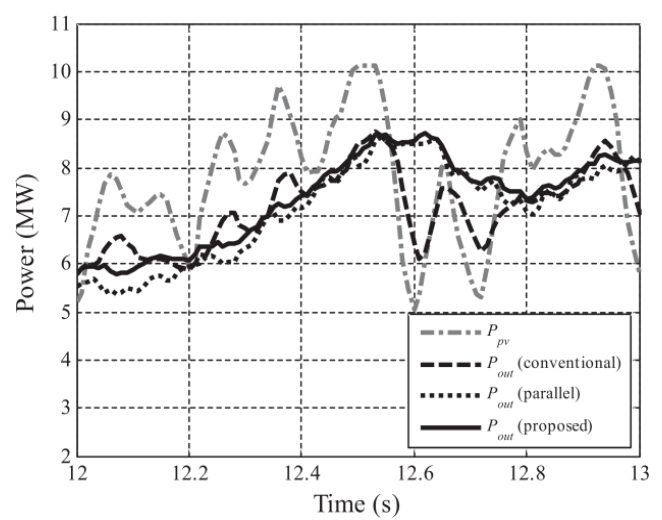

(b)

Fig. 5. Simulation results of output power fluctuation compensation: (a) during the entire daytime, and (b) during the time from 12 to $13 \mathrm{~s}$. 
where $\overline{v_{s c} n}$ is the averaged voltage of the SC during the one switching period. Therefore, when the sign of the modulating signal is positive, the SMES is charged, and if the sign of the modulating signal is negative, the SMES operates in discharging mode.

\section{Results and Analysis}

The performance of the proposed method is evaluated through a simulation based on the PSCAD/EMTDC ${ }^{\circledR}$ software, and the system is run with a $10 \mu$ s time-step from $6 \mathrm{~s}$ to $18 \mathrm{~s}$. The simulation results are shown in Fig. 5 and Fig. 6.

To evaluate the performance of the proposed SMES system, a case study of several types of SMES systems is carried out. The conventional SMES system consists of one $\mathrm{SC}$ and a DC/DC chopper. The parallel SMES system has the same configuration as the proposed SMES, but the interleaved control method is not applied.

As shown in Fig. 5, all SMES systems operate while compensating for power fluctuations. Nevertheless, the proposed system is comparable with others. During the time from 12.5 to $13 \mathrm{~s}$, the conventional system has power varying from $6.11 \mathrm{MW}$ to $8.75 \mathrm{MW}$, while the PV power changes from 5.3 MW to 10.12 MW as shown in Fig. 5(b).

The power of the parallel SMES system varies from 7.04 MW to $8.62 \mathrm{MW}$, and the proposed system has power fluctuations from 7.38 MW to 8.7 MW. The conventional system is insufficient for maximum fluctuation com-

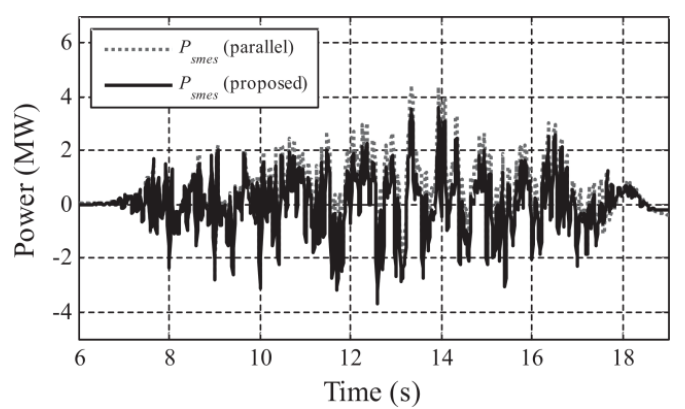

(a)

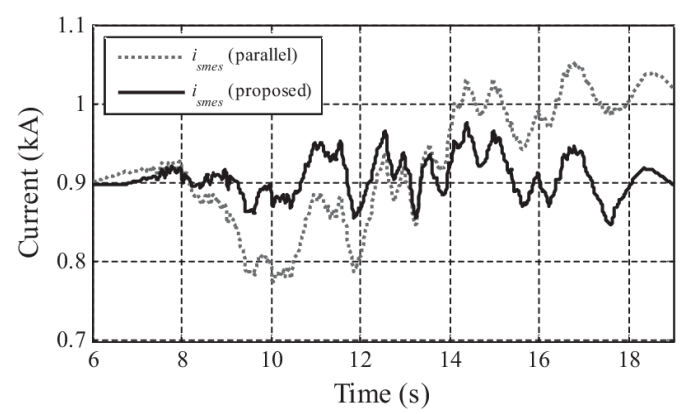

(b) pensation power, $P_{\text {smes max }}$, which can be expressed as

$$
P_{\text {smes_max }}=\sum_{n=1}^{N} v_{\text {smes }} \cdot i_{\text {smes_n }}
$$

The comparisons of the parallel SMES system and the proposed SMES system are shown in Fig. 6. The output power of the parallel SMES system for PV power compensation is larger than the power of the proposed system as shown in Fig. 6(a).

Moreover, in the case of parallel SMES system, the current of the SC at $6 \mathrm{~s}$ is significantly different than that at $18 \mathrm{~s}$ as shown in Fig. 6(b), and the difference of interleaving current with parallel method current is shown in Fig. 6(c). The reason of these problem is the VSC control reference error according to the voltage fluctuation of the DC link capacitor by affecting the ripple current of the SMES charging and discharging operation. Fig. 6(d) shows the voltage of the DC link capacitor.

In addition, the proposed SMES system improves the power quality. Table 2 shows the total harmonic distortion (THD) of the grid voltage. Because the DC link voltage is stabilized by the proposed method, the VSC control performance is also improved.

Table 2. THD of SMES system

\begin{tabular}{c|c}
\hline System & THD \\
\hline Conventional system & 1.367 \\
\hline Parallel system & 2.867 \\
\hline Proposed system & 1.318 \\
\hline
\end{tabular}

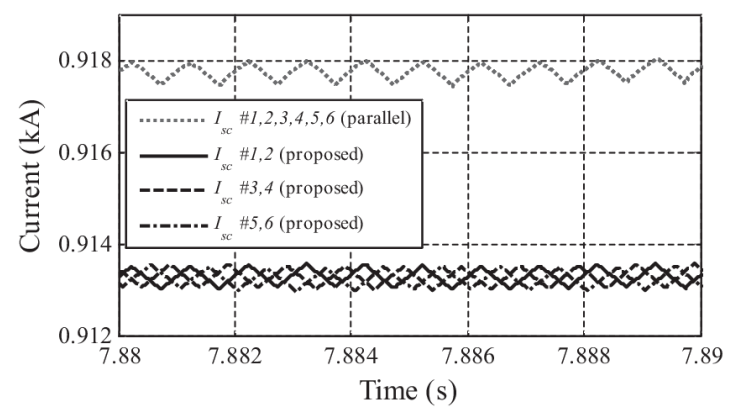

(c)

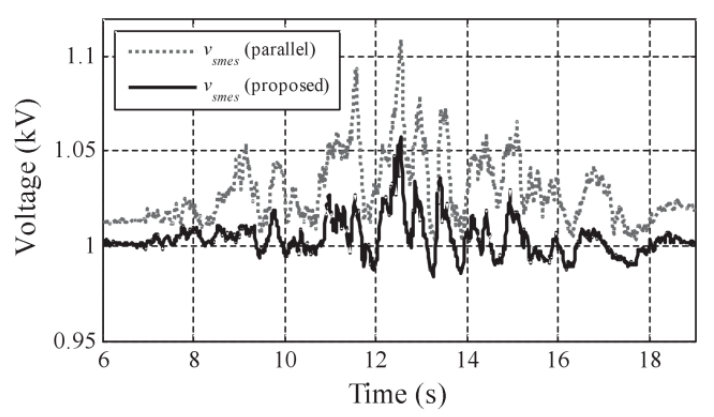

(d)

Fig. 6. Simulation results of SMES system: (a) output power of SMES; (b) average current of SC, (c) current of SC, and (d) voltage of DC link capacitor. 


\section{Conclusion}

This paper proposes the enhanced application of SMES for the effective compensation of power fluctuations based on the interleaving technique. The SMES system and the control method based on its parallel structure is proposed to improve the compensation capability and power quality. The dynamic performance of the system designed using the proposed method is evaluated with several case studies by time-domain simulations. The simulation results show that the proposed SMES system is able to enhance both compensation capability and power quality.

\section{Acknowledgements}

This work was supported partly by the National Research Foundation of Korea (NRF) grant funded by the Korea government (MEST) (No. 2011-0028065) and partly by Power Generation \& Electricity Delivery Core Technology Program of the Korea Institute of Energy Technology Evaluation and Planning (KETEP) granted financial resource from the Ministry of Trade, Industry \& Energy, Korea (20131020400920)

\section{References}

[1] S.H. Lee, G.T. Son, and Jung-Wook Park, "Power management and control for grid-connected DGs with intentional islanding operation of inverter," IEEE Trans. Power Sys., vol. 28, no. 4, pp. 12351244, May 2013.

[2] F. Diaz-Gonzalez, F. D. Bianchi, A. Sumper, and O. Gomis-Bellmunt, "Control of a flywheel energy storage system for power smoothing in wind power plants," IEEE Trans. Energy Convers., vol. 29, no. 1, pp. 204-214, Mar. 2014.

[3] Z. Zhou, F. Scuiller, J. F. Charpentier, M. E. H. Benbouzid, and T. Tang, "Power smoothing control in a grid-connected marine current turbine system for compensating swell effect," IEEE Trans. Sustain. Energy, vol. 4, no. 3, July 2013.

[4] H. Beltran, E. Bilbao, E. Belenguer, I. EtxeberriaOtadui, and P. Rodriguez, "Evaluation of storage energy requirements for constant production in PV power plants," IEEE Trans. Ind. Electron., vol. 60, no. 3, pp. 1225-1234, Mar. 2013.

[5] H. Beltran, M. Swierczynski, N. Aparicio, E. Belenguer, R. Teodorescu, and P. Rodriguez, "Lithium ion batteries ageing analysis when used in a PV power plant," in Proc. IEEE Int. Symp. on Industrial Electronics (ISIE), Hangzhou, China, May, 2012, pp. 1604-1609.

[6] B.-K. Kang, S.-T. Kim, S.-H. Bae, and J.-W. Park, "Effect of a SMES in power distribution network with PV system and PBEVs," IEEE Trans. Appl. Supercond., vol. 23, no. 3, pp. 5700104, Jun. 2013.

[7] I. Ngamroo and T. Karaipoom, "Improving lowvoltage ride-through performance and alleviating power fluctuation of DFIG wind turbine in DC microgrid by optimal SMES with fault current limiting function", IEEE Trans. Appl. Supercond., vol. 24, no. 5, pp. 5700805, Oct. 2014.

[8] M. Saejia and I. Ngamroo, "Alleviation of power fluctuation in interconnected power systems with wind farm by SMES with optimal coil size," IEEE Trans. Appl. Supercond., vol. 22, no. 3, pp. 5701504, Jun. 2012.

[9] A. M. Shiddiq-Yunus, M. A. S. Masoum, and A. AbuSiada, "Application of SMES to enhance the dynamic performance of DFIG during voltage sag and swell," IEEE Trans. Appl. Supercond., vol. 22, no. 4, pp. 5702009, Aug. 2012.

[10] S. Faias, P. Santos, J. Sousa, and R. Castro, "An overview on short and long-term response energy storage devices for power systems applications. System," in Proc. Int. Conf. Renewable Energies and Power Quality (ICREPQ'08), Santander, Spain, p. 6, Mar. 2008.

[11] S. Zhang and X. Yu, "A Unified Analytical Modeling of the Interleaved Pulse Width Modulation (PWM) DC-DC Converter and Its Applications," IEEE Trans. Power Electron., vol. 28, no. 11, pp. 5147-5158, Nov. 2013.

[12] T. F. Wu, Y. S. Lai, J. C. Hung, and Y. M. Chen, "Boost converter with coupled inductors and buckboost type of active clamp," IEEE Trans. Ind. Electron., vol. 55, no. 1, pp. 154-162, Jan. 2008.

[13] J.-T. Su and C.-W. Liu, "A novel phase-shedding control scheme for improved light load efficiency of multiphase interleaved DC-DC converters," IEEE Trans. Power Electron., vol. 28, no. 10, pp. 47424752, Oct. 2013.

[14] C. T. Pan and Y. H. Liao, "Modeling and control of circulating currents for parallel three-phase boost rectifiers with different load sharing," IEEE Trans. Ind. Electron., vol. 55, no. 7, pp. 2776-2785, Jul. 2008.

[15] J.-T. Su and C.-W. Liu, "A Novel Phase-Shedding Control Scheme for Improved Light Load Efficiency of Multiphase Interleaved DC-DC Converters," IEEE Trans. Power Electron., vol. 20, no. 10, pp. 47424752, Oct. 2013.

[16] F. Liccardo, P. Marino, G. Torre, and M. Triggianese, "Interleaved DC-DC converters for photovoltaic modules," in Proc. IEEE Int. Conf. Clean Electrical Power, 2007. ICCEP'07, Capri, Italy, pp. 201-207, May, 2007.

[17] J. H. Kim, W. S. Kim, S. Hahn, J. M. Lee, M. H. Rue, B. H. Cho, C. H. Im, and H. K. Jung, "Characteristic test of HTS pancake coil modules for small-sized SMES," IEEE Trans. Appl. Supercond., vol. 15, no. 2, 
pp. 1919-1922, Jun. 2005.

[18] S. A. D. Contreras, P. C. Cortizo, M. A. S. Mendes, "Simple control technique for interleaved inverters with magnetically coupled legs," IET Power Electron., vol. 6, no. 2, pp. 353-363, Feb. 2013

[19] S. Eckroad, "Program on Technology Innovation: Modeling of SMES and Its Integration to the Power Grid," EPRI, Palo Alto, CA, Oct. 2005.

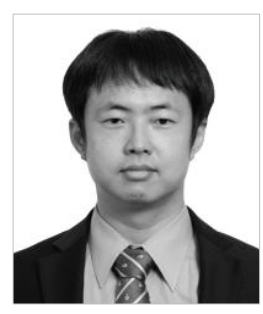

Seung-Tak Kim received the B.S. and Ph.D. degrees from the School of Electrical and Electronic Engineering, Yonsei University, Seoul, Korea, in 2009 and 2014, respectively. $\mathrm{He}$ is currently a Lead Researcher in the Hyundai Heavy Industries Co. Ltd, Yongin-si, Gyeonggi-do, Korea. His research interests are in control of renewable energies based systems, hardware implementation of grid-connected inverter with photovoltaic and energy storage devices, and energy management system for stabilization of distributed generation systems.

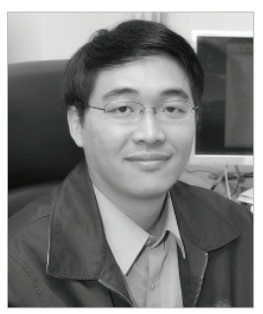

Jung-Wook Park was born in Seoul, Korea. He received the B.S. degree (summa cum laude) from the Department of Electrical Engineering, Yonsei University, Seoul, Korea, in 1999, and the M.S.E.C.E. and Ph.D. degrees from the School of Electrical and Computer Engineering, Georgia Institute of Technology, Atlanta, USA in 2000 and 2003, respectively. He was a Post-doctoral Research Associate in the Department of Electrical and Computer Engineering, University of Wisconsin, Madison, USA during 2003-2004, and a Senior Research Engineer with LG Electronics Inc., Korea during 2004-2005. He is currently an Associate Professor in the School of Electrical and Electronic Engineering, Yonsei University, Seoul, Korea. He is now leading the National Leading Research Laboratory (NLRL) designated by Korea government to the subject of integrated optimal operation for smart grid. His current research interests are in power system dynamics, renewable energies based distributed generations, power control of electric vehicle, and optimization control algorithms. Prof. Park was the recipient of the Young Scientist Presidential Award in 2013 from the Korean Academy of Science and Technology (KAST), Korea. 